\title{
Hierarchical protection control system of smart substations
}

\author{
Yuping ZHENG, Delin WANG, Zexin ZHOU, \\ Tuanjie CAO $(\square)$
}

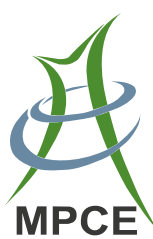

\begin{abstract}
This paper analyzes the problems of the relay protections and secondary circuits of traditional substations, and introduces the hierarchical protection and control system of smart substations based on the technologies like IEC 61850 Standard, electronic instrument transformer, process level network, and wide area optical fiber communication network, etc. The hierarchical protection and control system includes three levels: local area protection, substation area protection and control, and wide area protection and control. These three levels are combined to solve the problems of the relay protections in traditional substations, thus improving protection performance and control capability of the system.
\end{abstract}

Keywords Smart substation, Relay protection, Hierarchical protection and control system, Local area protection, Substation area protection and control, Wide area protection and control

\section{Introduction}

In the $21^{\text {st }}$ century, the smart grid has become a common choice for electric power industry with the energy and

CrossCheck date: 23 September 2014

Received: 27 June 2014/Accepted: 9 September 2014/Published online: 25 September 2014

(c) The Author(s) 2014. This article is published with open access at Springerlink.com

Y. ZHENG, T. CAO, NARI Group Corporation,

Nanjing 211106, China

(凹) e-mail: tuanjiecao@126.com

Y. ZHENG

e-mail: zhengyuping@sgepri.sgcc.com.cn

D. WANG, National Electric Power Dispatching Control Center,

Beijing 100031, China

Z. ZHOU, China Electric Power Research Institute,

Beijing 100192, China environment challenges. In 2009, the State Grid Corporation of China puts forward the concept of constructing "robust smart grid" including six parts: power generation, power transmission, power transformation, power distribution, power utilization, and dispatching, and it covers all voltage levels [1]. A substation is a node of the grid, and smart substation is an important connotation of smart grid. With intelligent primary equipment, electronic instrument transformers, and communication networks and systems following IEC 61850 standard, the substation is further automated and has some advanced application functions [2, 3].

Under the construction of smart substation, relay protection technology is undergoing a thorough and extensive reform. The last similar reform was occurred in 1990 when the microcomputer-based protection was developed to be the main solution. With a broader scope, this reform takes digitalized protection as the main solution, and includes instrument transformers and secondary circuits besides protection device itself [4].

Digitalized protection device receives the digital quantities of sampling values sent by the merging units of electronic instrument transformers through sample value (SV) communication interface, and the sampling of current and voltage is actually completed in electronic instrument transformers; the tripping command of digitalized protection device is sent to the intelligent breaker control of intelligent circuit breaker through optical fiber interface to trip and close the breakers. The application of electronic instrument transformers (and their merging units) and intelligent primary equipment (and its intelligent breaker control) has realized the digitalization of protective sampling and tripping, and improved the optical fiber application, digitalization, networking and even intelligentization of substation secondary circuits [5-7].

The communication technology is also important for the development of relay protection technology. Optical fiber Ethernet provides a condition for substation protection 
equipment to share current and voltage sampling values, state signals, and tripping and closing signals, meanwhile, the development of wide area communication technology even makes it possible for all protection equipments inside local grid to share information with functions meeting requirements.

Based on the present relay protection and related communication techniques of smart substation, this paper analyzes problems in relay protection for traditional substation, and puts forward a new hierarchical protection control system of smart substation.

\section{Problems of relay protection of traditional substations}

The problems and deficiencies of traditional substations are listed below:

1) Concerning the substations adopting EM type instrument transformers and secondary cable wiring, the transformer of current (TA) secondary cable is relatively long and the secondary load is heavy, which will easily induce saturation. Long secondary cable, large distribution area, complicated routes, large capacitance to ground, and serious interference and insulation problems bring about high fault probability in electrical secondary circuits, thus affecting the system reliability, in addition, the design, construction, debugging, maintenance, examination and repair, and reconstruction and expansion of the secondary circuit of traditional substations involve a large amount of work.

2) Many substations, especially those in urban areas, are with big loads and lots of devices, thus they are severely restricted by economy, environmental protection, and planning space, etc.

3) Primary equipment is developing to be intelligent, which could be realized by integration of intelligent components for measurement, control, monitoring and protection, etc, generally installed nearby the master equipment. The traditional mode is that secondary equipment is installed in main control room or relay protection cubicle, which does not meet the requirements of the primary equipment intelligentization and the closer integration of primary and secondary equipments.

4) The current and voltage signals on the secondary side of electromagnetic instrument transformers are transferred to the protection device through the secondary cable. Accordingly, the increase of the secondary equipment requires an increasing of secondary cable for connecting instrument transformer. The interlocking and blocking signals between secondary equipments, and the commands and signals between protection and circuit breaker are also transferred in one-to-one characteristics through secondary cable wiring. The relay protections and secondary circuits are configured according to bays. Each bay is naturally and physically independent, so that it is relatively easy to realize the isolation of faulty secondary equipment and circuits, hence the system will have relatively high reliability. On the other hand, it is relatively difficult to realize information intercommunication among all bays, repeated utilization of current and voltage quantities, interlocking and blocking information, as well as operation information. In order to realize the protection functions using multi-bay information, many secondary cables shall be added, thus the implementation is relatively difficult, which will restrict the functional improvement, optimization and supplementation of existing protection system.

5) The time delay is relatively long when the staged protection using single end electric quantities is used as the remote backup protection for lines or components. It is expected that some technologies can shorten the operation time of backup protections.

6) In case of change in the running mode of electric grid or the running state of protected equipment, a big workload will be required for modifying the settings of relay protections. A typical example is that, if some busbar protection stops, the time delay settings of zone II of opposite-side protections for all lines on the busbar need to be shortened.

7) If a substation loses all secondary DC power supplies for secondary short circuits or equipment explosion, etc, all protection devices in the substation will refuse to operate if they have faults in original protection scope. Here, it is necessary to coordinate the protection and control strategies for multiple associated lines and substations, to provide the best fault isolation and power supply recovery functions.

It will be possible to solve the above-mentioned problems with the development of intelligent substation, protection device design and manufacturing, network communication and optical fiber communication technologies. In the construction of smart substations, we can construct a hierarchical protection and control system of smart substations and improve the overall performance of relay protection system through comprehensive utilization of the basic supporting technologies like IEC 61850 standard, electronic instrument transformers, process level optical fiber Ethernet and wide area optical fiber communication, etc. 


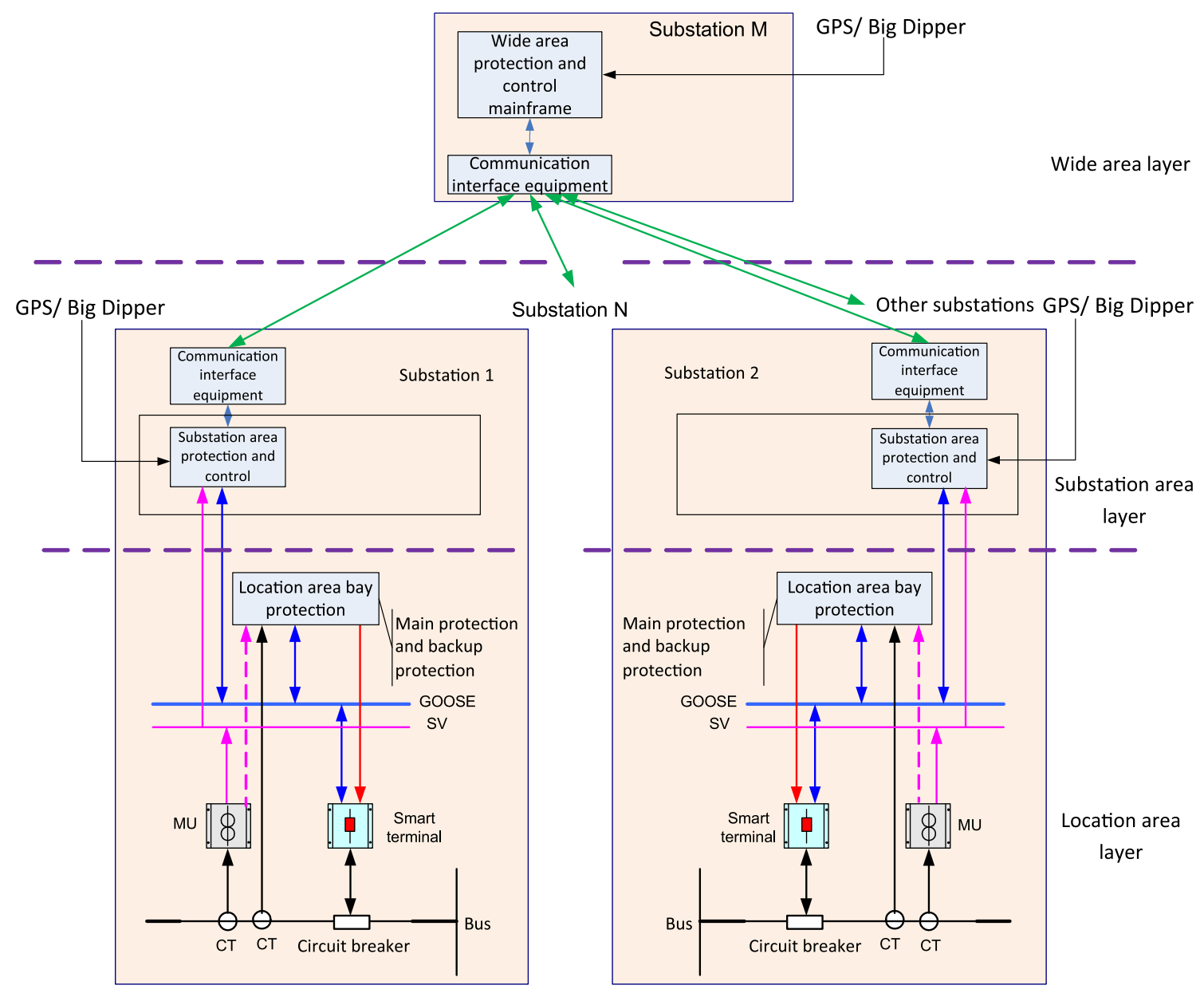

Fig. 1 Architecture of hierarchical protection and control system

\section{Hierarchical protection and control system of smart substations}

\subsection{Architecture}

The hierarchical protection and control system includes local area protection, substation area protection and control, and wide area protection and control. Local area protection faces single target object. It is independent in decision making with target object's own information and fast and reliable in eliminating the faults; Substation area protection and control faces towards one substation. It makes decision with the collected information of electrical quantities, binary quantities, and local area protection equipment in the substation. It realizes the redundancy and optimization of protections, performs and improves the safe and automatic control functions of the substation layer, meanwhile, it acts as a slave station of wide area protection and control; Wide area protection and control faces towards multiple substations. It makes decisions in a unified manner by using comprehensive information of each substation, thus it realizes related protection, security and stability control functions of local power grid.

The architecture of hierarchical protection and control system is shown in Fig. 1. The black connecting line is electric cable, the pink one is SV optical fiber cable, the blue one is generic object oriented substation event (GOOSE) optical fiber cable, and the green one is multiplexed or special optical fiber channel.

\subsection{Local area protection}

Local area protection mainly consists of existing traditional protection and digitalized protection. It is independently and dispersedly configured by bays, and adopts dual redundancy configuration for systems with $220 \mathrm{kV}$ and higher voltage levels. Its main task is to reliably and fastly eliminate faults. Local area protection intensifies main protection, simplifies backup protection, and gives priority to unit protection. It is impossible to consider the extreme operating mode of systems when configuring the protection settings. 
Local area protection device is directly connected with traditional transformers through electric cables or with the merging units of electronic transformer through optical fiber cable to obtain the sampling values of currents and voltages (direct sampling). Its protection functions can be realized without depending on external synchronizing block, thus ensuring the quick operation and reliability of local area bay protection. In addition, it directly controls the circuit breakers through electric cable connection and sends tripping and closing messages to the smart breaker controller of circuit breaker through directly-connected optical fiber cable in order to guarantee the quick operation of the protection. It also realizes the interlocking and blocking functions through GOOSE network, and gives full play to the information sharing advantage of IEC 61850. The faults of station level network in substations and inter-station communication system shall not affect the performance of local area bay protections.

Local area relay protection is installed near the protected equipment in order to shorten the distance from the protected equipment and realize the local area arrangement of protection device. Local area arrangement can shorten the electric cable and avoid related secondary problems of electrical secondary circuits. Meanwhile, it enables the best use of the floor space or building area of substations, resolves the difficulties in equipment arrangement, thus it is beneficial for the integrated installation of primary and secondary equipment.

Localization of protections is closely related to whether primary equipment is held indoors. For indoor GIS station and substations with some primary indoor equipment, the localized installation of protections is not so difficult, and protection devices may be installed locally in the collective control cabinet or independent control cabinet near indoor GIS equipment. For 10-35 kV equipment bays of switch cabinet type, protection devices shall be installed in the switch cabinet. For unattended outdoor open AIS or outdoor GIS substations, protections may be installed in secondary equipment integration module (a special container) or control cabinet with temperature and humidity adjustment functions (called intelligent control cabinet).

\subsection{Substation area protection and control}

Substation area protection is realized by substation area protection and control devices, which receives the information of multiple bays or the whole substation. It not only receives information by the single-bay protection, but also supplements and optimizes the existing protection system. For $110 \mathrm{kV}$ protection systems and lower voltage levels for which dual configuration is not provided, the centralized redundancy protection can be provided. Meanwhile, it can realize automatic control functions, for instance backup power supply automatic switch-on (auto backup) of the whole substation, under-frequency and under-voltage load shedding protection, and breaker failure protection, etc. Also, it can solve the problems of traditional backup protections that they can only obtain the information on electrical quantities and binary quantities of single bay, the operation time of backup protection is long, and the sensitivity and the selectivity cannot be simultaneously satisfied. In addition, it can also act as a slave station of wide area protection and control. Of course, the substation area protection and control must complete its own functions, independent of wide area protection and control, and local area protection devices.

Substation area protection and control device is configured with the following functions, which may be selected in certain applications [8].

1) It can complete the redundancy protection functions of $110 \mathrm{kV}$ single set configuration protection, including the redundancy protection of single-ended electrical quantity protection of $110 \mathrm{kV}$ circuits (including reclosing, excluding pilot protection), and $110 \mathrm{kV}$ bus coupler (bus sectioned) overcurrent protection. Redundancy is unnecessary in case both main protection and backup protection are configured for $110 \mathrm{kV}$ main transformer.

2) It can optimize and supplement the backup protection function, including supplementing the tripping failure protection function of $110 \mathrm{kV}$ circuit breaker, adding the accelerated overcurrent protection on low-voltage side of the main transformer, and shortening the time for fault elimination of backup protection. Also, the simple bus protection functions of $35 \mathrm{kV}$ and $10 \mathrm{kV}$ buses are constructed based on the GOOSE information on the protection starting and operation of each bay. According to circuit breaker operating mode in the substation, one zone of transformer backup protection operation logic is added: if this logic judges that the bus coupler (or bus sectioning) CB is in trip state before protection tripping, the time delay of tripping circuit breakers at both sides of transformer will be shortened.

3) It can complete the functions of safe and automatic control in a substation. Precisely, it can complete the under-frequency and under-voltage load shedding protection of the whole substation, strengthen the function of accurate load tripping based on traditional underfrequency and under-voltage load shedding protection, and realize comprehensive decision making with the combination of off-line strategy and on-line measurement information. It completes auto backup of the whole substation and overload intertripping of substation, integrate and realizes the power source automatic switching (PSAS) function of each voltage level in substation area protection and control device, optimizes the logic of PSAS, realizes the linkage of PSAS with 
section power flow and load state, and also realizes PSAS of complicated main wiring and the main wiring with small power supply outgoing line. Meanwhile, it can provide the functions like intertripping of loads upon main transformer overload, and equal division of loads on bus or main transformer, etc.

4) It can act as a slave station (or execution station) of wide area protection and control. Precisely, it can complete the acquisition, processing and transmission of substation area information, and execute the function as a slave station of regional grid protection and control.

The substation area protection and control device acquires sampling values through process level SV network, sends out tripping and closing commands, and receives information on the state of primary equipment and the interlocking and blocking of secondary equipment through GOOSE network. The SV network of substation process level and the GOOSE network may be integrated. The substation area protection and control device has a proper quantity of communication interfaces, which adapts to various networking modes on station and process level of smart substations. The networking mode in substations shall avoid network storm.

Substation area protection and control device is a bay level device in IEC 61850 standard. This device accesses the sampling value and GOOSE messages of multiple bays through the process level SV network and GOOSE network switch, and it has relatively big data flow and many network ports. The device enhances its data processing capacity by dints of high-performance processor, internal high-speed communication link and FPGA device.

The substation area protection and control device acquires sampling values via network switch. In order to ensure data synchronization, some functions depend on external clock synchronization. IRIG-B code is generally adopted for time synchronization, and IEEE 1588 mode may also be adopted. When the time synchronization system in the substation loses big dipper or GPS satellite signal, its master clock shall have time keeping function, and the precision of time can meet the requirements of relevant protection and control functions [9].

The substation area protection and control functions shall be realized without depending on external time synchronization system to the greatest extent $[10,11]$.

The communication of the substation area protection and control device with the master station and other stations of wide area protection and control shall meet the requirements of wide area protection and control.

\subsection{Wide area protection and control}

Wide area protection and control considers the following problems in grid operation:
1) Supplementation and optimization of existing protection system: For grids of $110 \mathrm{kV}$ and lower voltage level, it lays particular emphasis on the relay protection of local grids. It constructs the redundancy protection of local grids based on wide area information. For grids with complicated running modes, the operation time of backup protection is long, and the sensitivity and selectivity cannot be simultaneously satisfied. It can simplify the cooperation with backup protection and shorten the operation time of backup protection by using the information of local grids. For substations losing secondary DC power supply, it can coordinate the protection and control strategy of surrounding substations and provide the best fault isolation and power supply recovery functions.

2) Optimization of protection settings: The information of regional grids is used to identify the topology structure and equipment running state of grids, and to optimize the settings of backup protection.

3) Optimization of security and stability control: For systems of $220 \mathrm{kV}$ and above, it lays particular emphasis on the security and stability control functions to realize the coordination among interrelated regional security and stability control systems, the regional intelligent distribution of under-frequency load shedding and under-voltage load shedding belonging to the third line of defense system, the coordinated control of multi-profile out-of-step separation under complicated networking conditions, the AC/DC coordinated control under the condition of AC/DC networking and PSAS between substations in wide area scope.

The wide area protection and control of $110 \mathrm{kV}$ and lower level lays particular focus on the relay protection of local grids, and is selected from some substations in local grids on the demand of such local grids. Wide area protection and control system is formed by connecting the mainframe of some substations with the slave stations of other multiple substations through power communication network. The slave stations here may be are realized by the substation area protection and control slave stations of each substation. The system structure and equipment configuration are shown in Fig. 2. The master station (mainframe) is arranged in the substation of $220 \mathrm{kV}$ or above level, or of $110 \mathrm{kV}$. In order to guarantee the operation reliability, and considering the flexibility of configuration, we may arrange 2 sets of wide area protection and control mainframes which are simultaneously operated and acted as standby for each other. When one set fails, for instance due to overhaul or off-line configuration, the other set will still execute online protection and control functions.

The wide area protection and control takes higher requirements on the real-time performance, reliability and 


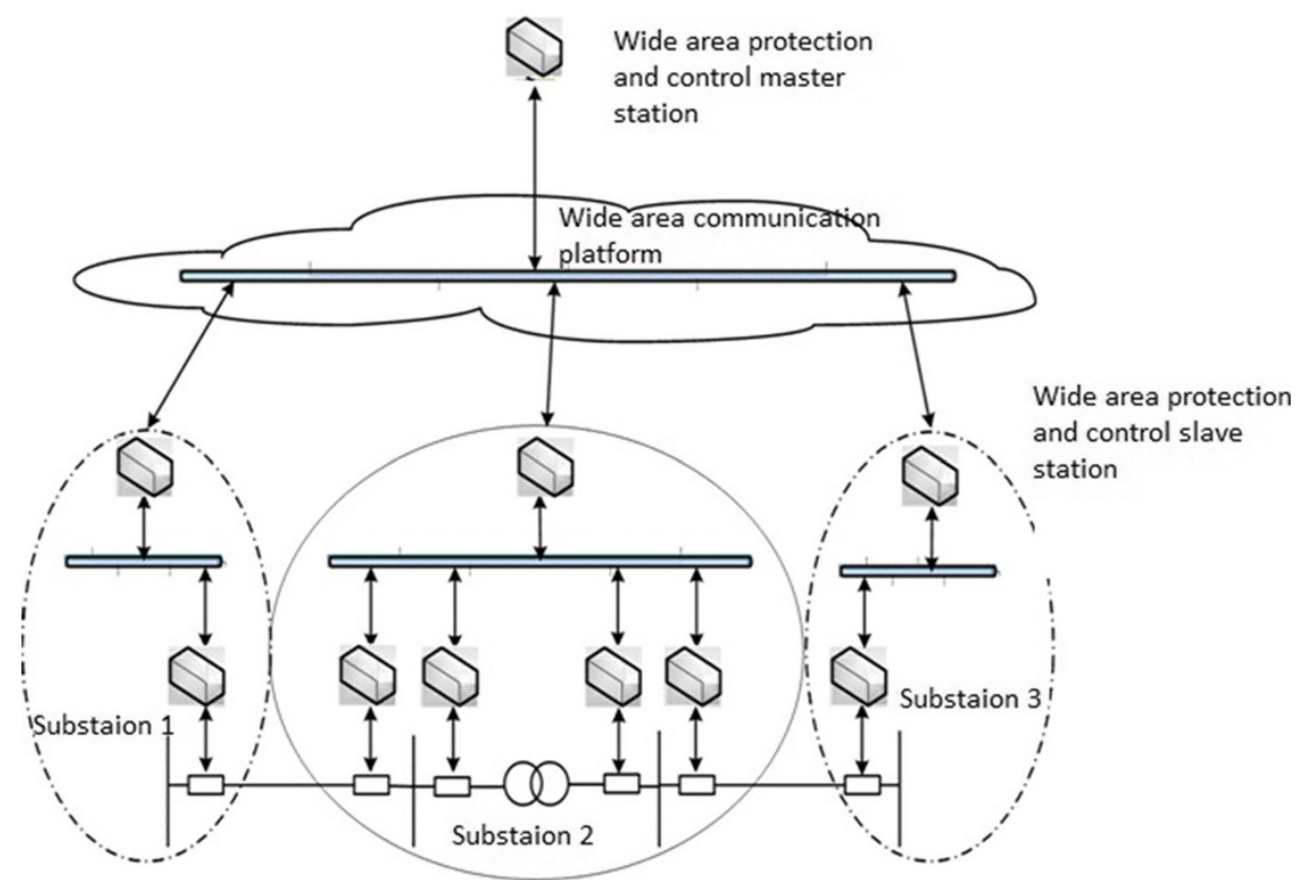

Fig. 2 Schematic diagram of wide area protection and control system of $110 \mathrm{kV}$ and lower level

security of data transmission. The communication system applied to public networks at present is deficient for protection service in terms of resource allocation, interface design, transmission performance, and operation and maintenance. In order to ensure the communication indexes of wide area protection and control service, the protection service and other services are treated differently, and special network is constructed to carry the protection service and isolate protection service from other services physically, in addition, special equipment will be developed based on existing public network equipment aiming at relatively high requirements on the performance of protection service [12].

According to the development of optical fiber transmission network technology at present, synchronous digital hierarchy (SDH) technology or packet transmission network (PTN) technology may be used to construct the hierarchical protection and control system network of smart substations [13]. Fig. 3 shows a SDH-based communication networking structure.

Wide area protection and control functions shall be realized without depending on external time synchronization system to the greatest extent. In case time synchronization system is adopted, such as Big Dipper or GPS satellite time synchronization, Big Dipper system for time synchronization shall prevail. If allowed by conditions, the ground time synchronization system is recommended.

Wide area protection and control equipment is functioned to be time keeping. If the time synchronization signal source

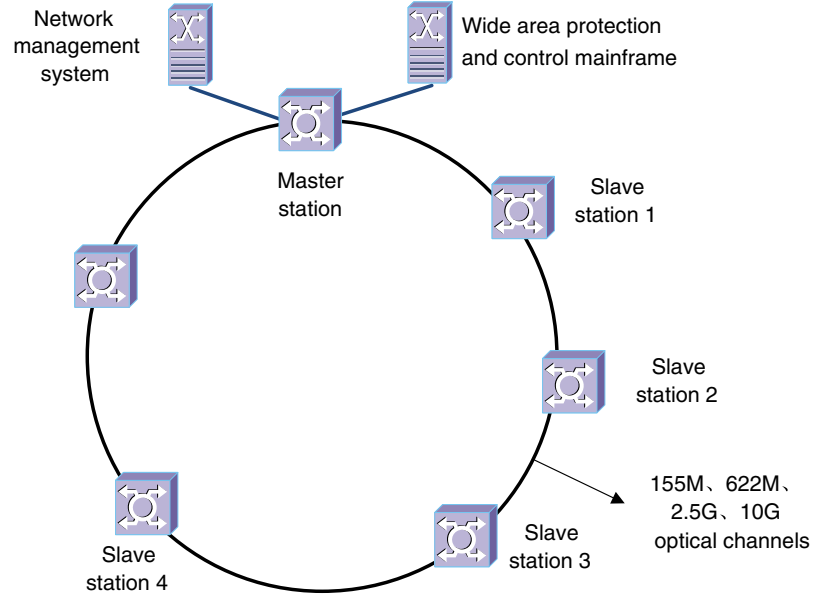

$\mathrm{SDH}$

Fig. 3 SDH-based communication networking structure

system is lost, the time keeping precision can meet the requirements by related protection and control functions. If the time keeping precision is out of the permitted scope, the protection and control functions shall be blocked.

The wide area protection and control system of $220 \mathrm{kV}$ and above levels takes regional stability control system as the main body. The stability control system is configured by layers and regions. The equipment configuration and installation location of master station, slave station, and 
execution station shall meet the requirements in the security and stability control of grids. If the existing regional security and stability control system requires without depending on external time synchronization, such requirements shall be followed.

\section{Conclusions}

Wide area protection and control collects the measurement, control and protection information of each substation and sends out commands through the substation area protection and control device. The substation area protection and control device collects local area protection information and sends out control commands directly, for instance, without local area protection. Local area protection function is realized without depending on substation area and wide area protection and control systems, but executes necessary information exchange. Local area bay protection, substation area protection, and wide area protection and control are combined organically to form a complete hierarchical protection and control system, which not only guarantees the independence, reliability, and quick operation of bay protection, but also uses substation area and wide area protection and control to solve the problems of relay protection for traditional substations, and improve protection performance and control capability of system security and stability.

The six experimental projects completed by State Grid Corporation of China (SGCC) had been put into operation at the end of 2013, and the local area protections and the substation area protection, as well as control equipment were used in following substations: $220 \mathrm{kV}$ Dashiqiao Substation in Chongqing, $220 \mathrm{kV}$ Future City Substation in Beijing, $110 \mathrm{kV}$ Future City Substation in Wuhan, $110 \mathrm{kV}$ Yetang Substation in Shanghai, $110 \mathrm{kV}$ High \& New Technological Park Substation in Tianjin, and $110 \mathrm{kV}$ Haijingluo Substation in Beijing.

SGCC has compiled and issued enterprise technical Standards Q/GDW-441 "Technical Specifications for Smart Substation Relay Protection" and "General Technical Requirements on Smart Substation Relay Protection" etc., to standardize the technical requirements on local area protections.

Wide area protection and control system is in the process of research and development. The issues need further studies include: 1) the orientation and zoning principles of wide area relay protection application areas, and information exchange between zones; 2) the cooperation and coordination between wide area relay protection and local backup protection; 3 ) the cooperation between wide area relay protection and security, and stability control system; and 4) the research and realization of wide area communication and time synchronization technology, etc.
Open Access This article is distributed under the terms of the Creative Commons Attribution License which permits any use, distribution, and reproduction in any medium, provided the original author(s) and the source are credited.

\section{References}

[1] Liu ZY (2010) Robust smart grid technology. China Electric Power Press, Beijing, China (in Chinese)

[2] Q/GDW 383-2009 (2009). Technical guide for smart substation. State Grid Corporation of China, Beijing (in Chinese)

[3] IEC 61850 (all parts) (2004) Communication networks and systems in substations

[4] Cao TJ, Huang GF (2013) Relay protection technology and application of smart substation. China Electric Power Press, Beijing (in Chinese)

[5] Q/GDW 441-2010 (2010) Technical specifications for relay protection of smart substation. State Grid Corporation of China, Beijing (in Chinese)

[6] IEC 60044-8:2002 (2002) Instrument transformers-part 8: electronic current transformers

[7] IEC 60044-7:1999 (1999) Instrument transformers-part 7: electronic voltage transformers

[8] NARI Technology Development Co Ltd. (2013) Technical specification of NSR310 substation area protection and control device. NARI Technology Development Co Ltd, Nanjing (in Chinese)

[9] Xie L, Huang GF, Shen J (2009) Design of high precision synchronous sampling clock in digital substations. Autom Electr Power Syst 33(1):61-65 (in Chinese)

[10] Cao TJ, Yin XG, Zhang Z et al (2007) Discussion on data synchronization of electronic instrument transformers. P CSUEPSA 19(2):108-113 (in Chinese)

[11] Cao TJ, Yu ZF, Wu CH (2009) Data synchronization method of optical fiber differential protection connected with electronic transformers. Autom Electr Power Syst 33(23):65-68 (in Chinese)

[12] Xu TQ, Yin XG, You DH et al (2008) Communication network for three-level wide area protection system. Autom Electr Power Syst 32(16):28-33 (in Chinese)

[13] Li RZ, Wang HY, Yang X et al (2011) The planning and construction scheme of PTN data transport network of Shandong Electric Power Company. Telecommun Electr Power Syst 32(6):12-16 (in Chinese)

Yuping ZHENG male, doctor, professor-level senior engineer. His research fields conclude the research, development and management of relay protection for electric power systems.

Delin WANG male, master, senior engineer. His research fields conclude professional management, dispatching operation and technical research of relay protection.

Zexin ZHOU female, doctoral candidate, senior engineer. His research fields conclude the relay protection, dynamic simulation, protective operation, and statistical analysis of electric power system.

Tuanjie CAO master, senior engineer. His research fields conclude microcomputer relay protection and automatic safety device of electric power system, and he is a communication author. 